\title{
TU/e EmonOWEN

\section{Flexible resource provisioning of coherent PONs based on Non-Orthogonal Multiple Access and CAP signals}

\section{Citation for published version (APA):}

Izquierdo, D., Altabas, J. A., Clemente, J., Millan, P., Lazaro, J. A., Rommel, S., Puerta, R., Vegas Olmos, J. J., Monroy, I. T., \& Garces, I. (2020). Flexible resource provisioning of coherent PONs based on Non-Orthogonal Multiple Access and CAP signals. In 45th European Conference on Optical Communication (ECOC 2019) [9125491] (IET Conference Publications; No. CP765). Institution of Engineering and Technology (IET). https://doi.org/10.1049/cp.2019.0763

DOI:

10.1049/cp.2019.0763

Document status and date:

Published: 30/06/2020

\section{Document Version:}

Accepted manuscript including changes made at the peer-review stage

\section{Please check the document version of this publication:}

- A submitted manuscript is the version of the article upon submission and before peer-review. There can be important differences between the submitted version and the official published version of record. People interested in the research are advised to contact the author for the final version of the publication, or visit the $\mathrm{DOI}$ to the publisher's website.

- The final author version and the galley proof are versions of the publication after peer review.

- The final published version features the final layout of the paper including the volume, issue and page numbers.

Link to publication

\section{General rights}

Copyright and moral rights for the publications made accessible in the public portal are retained by the authors and/or other copyright owners and it is a condition of accessing publications that users recognise and abide by the legal requirements associated with these rights.

- Users may download and print one copy of any publication from the public portal for the purpose of private study or research.

- You may not further distribute the material or use it for any profit-making activity or commercial gain

- You may freely distribute the URL identifying the publication in the public portal.

If the publication is distributed under the terms of Article 25fa of the Dutch Copyright Act, indicated by the "Taverne" license above, please follow below link for the End User Agreement:

www.tue.nl/taverne

Take down policy

If you believe that this document breaches copyright please contact us at:

openaccess@tue.nl

providing details and we will investigate your claim. 


\title{
Flexible resource provisioning of coherent PONs based on Non-Orthogonal Multiple Access and CAP signals David Izquierdo ${ }^{1,2 *}$, Jose A. Altabas ${ }^{3,2}$, Jesus Clemente', Pablo Millan', Jose A. Lazaro ${ }^{4}$, Simon Rommel ${ }^{5}$, Rafael Puerta ${ }^{6}$, Juan J. Vegas Olmos $^{7}$, Idelfonso Tafur Monroy ${ }^{5}$, Ignacio Garces ${ }^{2}$ \\ ${ }^{1}$ Centro Universitario de la Defensa, Zaragoza, Spain \\ ${ }^{2}$ Aragon Institute of Engineering Research (I3A), University of Zaragoza, Zaragoza, Spain \\ ${ }^{3}$ Bifrost Communications, Lyngby, Denmark \\ ${ }^{4}$ Universitat Politècnica de Catalunya, Barcelona, Spain \\ ${ }^{5}$ Institute for Photonic Integration (IPI), Eindhoven University of Technology, Eindhoven, the Netherlands \\ ${ }^{6}$ Development Unit Networks, Ericsson AB, Stockholm, Sweden \\ ${ }^{7}$ Mellanox Technologies, Roskilde, Denmark \\ *d.izquierdo@unizar.es
}

Keywords: COHERENT, PON, NOMA, CAP, OPTICAL ACCESS

\begin{abstract}
Non-Orthogonal Multiple Access (NOMA) technique and Carrierless Amplitude Phase (CAP) modulation have been used to demonstrate pay-as-you-grow coherent Passive Optical Networks (PON) and providing a 10 Gbps aggregate data rate.
\end{abstract}

\section{Introduction}

Traffic demand over optical access networks is growing exponentially due to new multimedia streaming services, Internet of Things (IoT) applications and machine-to-machine communications [1]. These high bandwidth connections require new access techniques that not only use the current and congested networks, but also increase the number of users per wavelength or span the networks to farther distances. In a common Passive Optical Network (PON) scenario, where the downstream signal is divided between several users using power splitters and user data are time domain multiplexed (TDM), when the service provider needs to add new users, it will need to deploy a new PON and a new Optical Line Terminator (OLT) in the same Central Office (CO).

In this scenario, the design of new approaches to increase both, capacity and number of users, in a flexible way is essential. In this work, Non-Orthogonal Multiple Access (NOMA) technique and Carrierless Amplitude Phase (CAP) modulation are combined with a coherent reception scheme in order to allow flexible resource provisioning, increasing at the same time the number of users and the range of the network. NOMA-CAP has been successfully tested for radio-over-fibre links in W-band [2], but has not been studied for PONs. High data rate demands require a migration to advanced and flexible modulations such as CAP modulation [3], while NOMA is a promising candidate to enhance both capacity and flexibility of the network [4]. Finally, coherent PONs provides a way to increase the available power budget (thus, the split level and range of the PON) and the spectral efficiency (enabling UltraDense Wavelength Division Multiplexing (UDWDM)).

\section{Proposed PON architectures}

NOMA-CAP uses constellation multiplexing of user data, allowing direct sharing of time and frequency resources between them. We multiplex two users with two different optical power multiplexing levels, one for the near (weak) user and other for the far (strong) user, which are denoted as PON1 and PON2. Using NOMA-CAP, new networks can be connected to a previous one, multiplexing user data of each network. This solution reduces the deployment cost by the integration of several PONs in the same OLT and increases its user density. We will study the performance of three different PONs architectures, shown in Fig. 1. In the first one (a) a new PON is added to an existing one, while in the second (b) several PONs are added. In the last scenario (c) we study the integration of several PONs in a unique and bigger network.
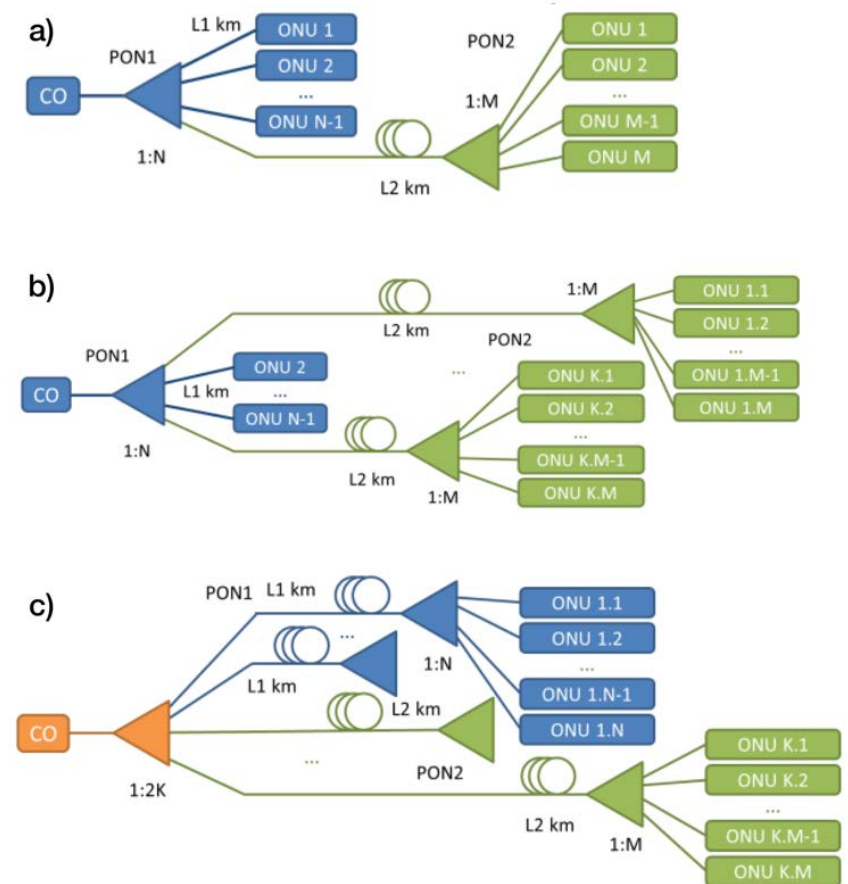

Fig. 1 Studied NOMA-CAP PON integration architectures: a) PON1+PON2 b) PON1+k×PON2 c) $k \times$ PON1 + $k \times$ PON2. 


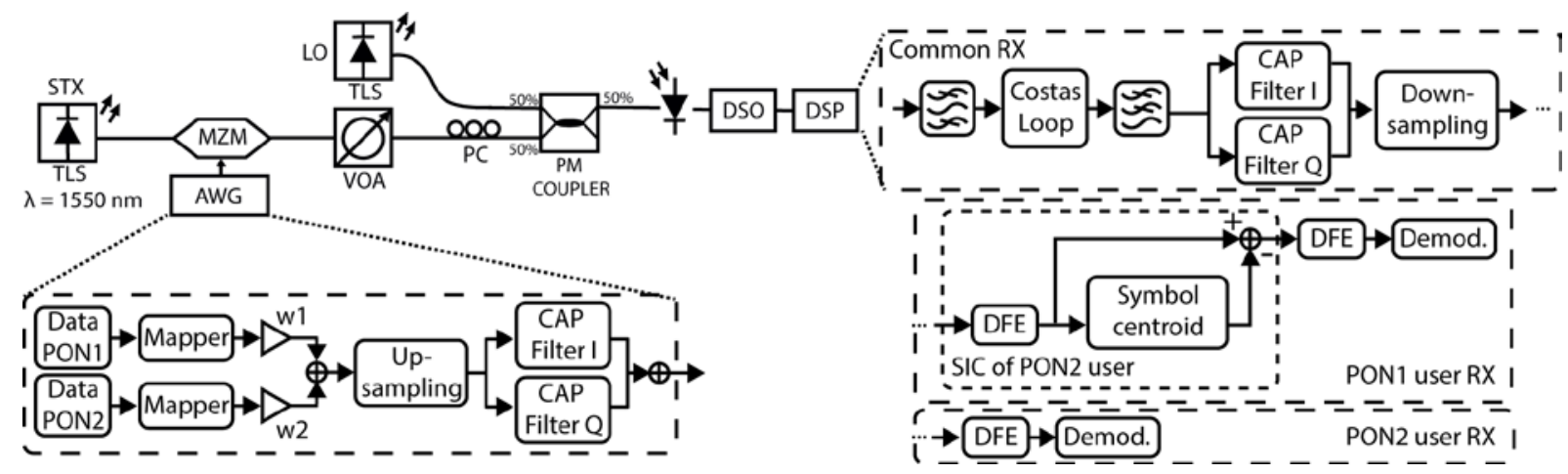

Fig. 2 Experimental setup.

\section{Experimental Setup}

Fig. 2 shows the experimental setup for the evaluation of the NOMA-CAP medium access technique. The transmitted NOMA-CAP signal is digitally generated by the constellation multiplexing of two users, one of each sub-network PON1 and PON2. The 2.5 Gbaud data of each user is encoded with a CAP4 format and, in the constellation multiplexing, user from PON2 has a higher weight than user from PON1 to compensate the extra losses to reach this sub-network. Once the NOMA symbols are generated, with an aggregated data rate of 10 Gbps, they are upsampled and passed through a CAP transmitter based on two orthogonal filters. The output signal of the CAP transmitter is generated by a 12 GSps Arbitrary Waveform Generator (AWG) that drives a null-point biased Mach-Zehnder Modulator (MZM). The optical transmitted signal is a DSB (Double Side Band) modulation instead of the common CAP signal based on IM (Intensity Modulation) to increase the power efficiency.

The received signal is mixed with a $+5 \mathrm{dBm}$ local oscillator (LO) in for coherent heterodyne detection with a single-ended $10 \mathrm{GHz}$ photodiode. The $\mathrm{LO}$ is shifted $5.5 \mathrm{GHz}$ from the central wavelength of the received signal to reduce the interference of the direct detection of the CAP signal. The detected signal is digitalized by a $20 \mathrm{GHz}$ Digital Storage Oscilloscope (DSO) and then digitally processed (DSP). The digital receiver consists of a band-pass filter for noise reduction and a Costas loop for carrier recovery and baseband conversion. The baseband signal is then low-pass filtered and CAP data is extracted; this part is common to both users. PON1 users implement Successive Inference Cancellation (SIC) to remove the PON2 user data. The first step of the SIC is a decision feedback equalizer (DFE) with 30 forward and 20 backward taps. After that, the symbol centroid of the PON2 user data is assigned by k-means algorithm and subtracted from the equalized signal. After the SIC, a second DFE with the same parameters is applied again and PON1 user data is finally demapped. In the case of PON2 users, SIC is not required and the DFE and demapping are performed directly.

\section{Results}

The NOMA-CAP technique performance has been evaluated using bit error rate (BER) measurements for several power ratios for the constellation multiplexing of two users. As can be seen in Fig. 3, where BER for both PON1 and PON2 users is plotted in terms of received power and power ratio between users, the sensitivity limits are not achieved with power ratios below $4 \mathrm{~dB}$. The sensitivity limits correspond with BER values of $3.8 \times 10^{-3}$ and $1.32 \times 10^{-2}$ for standard forward error corrections (FEC) with $7 \%$ and $25 \%$ of overhead $(\mathrm{OH})$ [5]. Moreover, the sensitivity for a PON1 user is always worse than the sensitivity for a PON2 user independently of the power ratio due to the error propagation in the SIC. Any errors in the SIC calculation of the symbol centroid of PON2 user will affect the decoding of PON1 data and thus it will cause a higher BER.
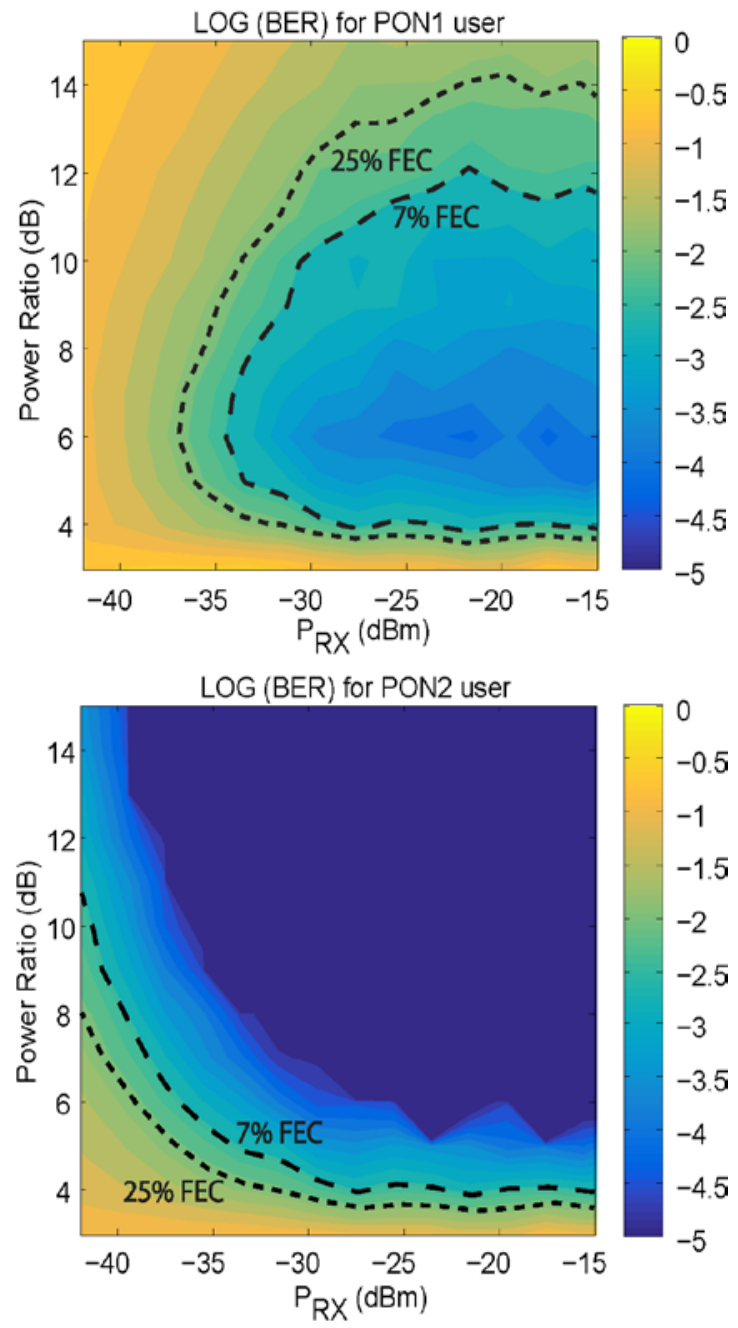

Fig. 3 Limit of BER values for PON1 and PON2 users. 
Table 1 Results of different scenarios of the proposed NOMA-CAP Coherent PONs architectures.

\begin{tabular}{|c|c|c|c|c|c|c|c|c|c|c|}
\hline \multirow[b]{2}{*}{ Configuration } & \multirow{2}{*}{$\begin{array}{c}\text { Power } \\
\text { Ratio }\end{array}$} & \multicolumn{4}{|c|}{ PON 1} & \multicolumn{4}{|c|}{ PON 2} & \multirow{2}{*}{$\begin{array}{l}\text { Total } \\
\text { users }\end{array}$} \\
\hline & & $\begin{array}{l}\text { Power } \\
\text { Budget }\end{array}$ & $\begin{array}{c}\text { Reach } \\
\text { (L1) }\end{array}$ & $\begin{array}{l}\text { Splitting } \\
\text { ratio }(\mathrm{N})\end{array}$ & \# users & $\begin{array}{l}\text { Power } \\
\text { Budget }\end{array}$ & $\begin{array}{c}\text { Reach } \\
\text { (L2) }\end{array}$ & $\begin{array}{l}\text { Splitting } \\
\text { ratio }(\mathrm{N})\end{array}$ & $\begin{array}{c}\# \\
\text { users }\end{array}$ & \\
\hline \multirow[t]{3}{*}{ PON1 + PON2 } & $6 \mathrm{~dB}$ & $36.5 \mathrm{~dB}$ & $40 \mathrm{~km}$ & $1 \times 32$ & 31 & $39 \mathrm{~dB}$ & $40 \mathrm{~km}$ & $1 \times 16$ & 16 & 47 \\
\hline & $8 \mathrm{~dB}$ & $35 \mathrm{~dB}$ & $40 \mathrm{~km}$ & $1 \times 32$ & 31 & $42 \mathrm{~dB}$ & $40 \mathrm{~km}$ & $1 \times 32$ & 32 & 63 \\
\hline & $10 \mathrm{~dB}$ & $32 \mathrm{~dB}$ & $40 \mathrm{~km}$ & $1 \times 64$ & 63 & $43.5 \mathrm{~dB}$ & $40 \mathrm{~km}$ & $1 \times 16$ & 16 & 79 \\
\hline PON1 + 4·PON2 & $10 \mathrm{~dB}$ & $32 \mathrm{~dB}$ & $40 \mathrm{~km}$ & $1 \times 64$ & 60 & $43.5 \mathrm{~dB}$ & $40 \mathrm{~km}$ & $4(1 \times 16)$ & 64 & 124 \\
\hline 16:PON1+16·PON2 & $10 \mathrm{~dB}$ & $32 \mathrm{~dB}$ & $20 \mathrm{~km}$ & $16(1 \times 8)$ & 128 & $43.5 \mathrm{~dB}$ & $80 \mathrm{~km}$ & $16(1 \times 8)$ & 128 & 256 \\
\hline
\end{tabular}

According to Fig. 3, a PON2 user would prefer a scenario with a high power ratio since a sensitivity of at least $-37 \mathrm{dBm}$ will be always achieved with power ratios above $6 \mathrm{~dB}$ for a $7 \%$ FEC. If higher sensitivities are required, the power ratio can be increased, for example to $10 \mathrm{~dB}$, where a sensitivity of $-41.5 \mathrm{dBm}$ for a PON2 user will be achieved. On the other hand, PON1 user has an optimum power ratio of $6 \mathrm{~dB}$, where the sensitivity of the PON1 user will be $-34.5 \mathrm{dBm}$ (7\% FEC). If the ratio decreases enough, e.g. below $4 \mathrm{~dB}$, PON2 user centroids cannot be correctly calculated in the SIC and therefore all these errors will be propagated to the PON1 user. If the power ratio increases, the PON2 user centroids will be calculated better but the PON1 user will have less power to be demodulated and its sensitivity will be degraded. For example, with $10 \mathrm{~dB}$ of power ratio, the sensitivity for PON1 user with $7 \%$ FEC is $-30.5 \mathrm{dBm}, 4 \mathrm{~dB}$ worse than $6 \mathrm{~dB}$ power ratio.

Therefore, the power ratio selection has to be balanced depending on the actual PON deployment scenario to be implemented. The NOMA-CAP technique permits a pay-asyou-grow PON architecture. If the PON operator requires to increase the number of users, the NOMA-CAP concept can be introduced replacing one of the users of the PON1 by a new network PON2. Selecting the different power ratios, different architectures can be implemented, as shown in Table 1 where results for three different PONs scenarios based on the configurations shown in Fig. 1 are presented. For this table, optical power budgets have been calculated using receiver sensitivities for different optical power ratios at 7\% FEC and an optical emitted power of $+2 \mathrm{dBm}$.

Firstly, it is presented the data corresponding to the Fig.1 (a) configuration, PON1+PON2, for different optical power ratios, where a new PON (PON2) is deployed from one of the branches of an existing PON1. The NOMA-CAP technique can be applied in this scenario to include a strong user that will be used for the new PON2. According to the optical power budget shown in the table, it is possible, for a power ratio of $6 \mathrm{~dB}$, to introduce a new $1 \times 16$ PON from one branch of the $1 \times 32$ PON1, increasing the number of users. The number of users may keep growing using higher power ratios, as can be seen from the table. However, for higher optical power ratios the optical power budget of PON1 decreases rapidly.

If the PON operator necessities continue growing, more users of PON1 can be replaced for new PONs, increasing the total number of users. As can be seen in Table 1, the number of users can be increased up to 124 by including 4 new PON2 connected to 4 branches of the original PON1.
As a final scenario, several PON1 and PON2 can be nested achieving a larger number of users. For example, given the optical power budgets obtained for this case, up to $321 \times 8$ different PONs can be deployed from one OLT, obtaining a number of 256 possible users, 16 of them will be near $(20 \mathrm{~km})$ PON1s, while the rest will be far $(80 \mathrm{~km})$ PON2s.

\section{Conclusions}

Non-Orthogonal Multiple Access and CAP modulation for Coherent Passive Optical Access Networks has been proposed and evaluated in different scenarios of PONs and users configurations based on experimental receiver sensitivities. NOMA-CAP have been used to demonstrate a pay-as-yougrow PON architecture using coherent detection and providing a near $10 \mathrm{Gbps}$ aggregate data rate.

\section{Acknowledgements}

This work was supported in part by the Diputacion General de Aragon under Grant T20_17R, by the Spanish MINECO projects FOANT (TEC2017-85752-R) and ALLIANCE (TEC2017-90034-C2-2-R), co-funded by FEDER, projects UZCUD2018-TEC-07 and CUD2018-08, and by a MECD FPU Grant (FPU-13/00620).

\section{References}

[1] Cisco Visual Networking Index: Global Mobile Data Traffic Forecast Update, 2016-2021, White Paper.

[2] Altabas, J.A., Rommel, S. Puerta. R., et al.: 'Nonorthogonal Multiple Access and Carrierless Amplitude Phase Modulation for Flexible Multiuser Provisioning in 5G Mobile Networks', Journal of Lightwave Technology, 2017, 35, (24), pp. 5456-5463.

[3] Dia, L., Wang, B., Yuan, Y., et al., 'Non-orthogonal multiple access for 5G: Solutions, challenges, opportunities, and future research trends', IEEE Communications Magazine, 2015, 53, (9), pp. 74-81.

[4] Iglesias Olmedo, M., Zuo, T., Jensen, J.B., et al., "Multiband carrierless amplitude phase modulation for high capacity optical data links," Journal of Lightwave Technology, 2014, 32, (4), pp. 798-804.

[5] ITU, "Forward error correction for high bit-rate DWDM submarine systems,” Rep. ITU-T G.975.1, 2004. 